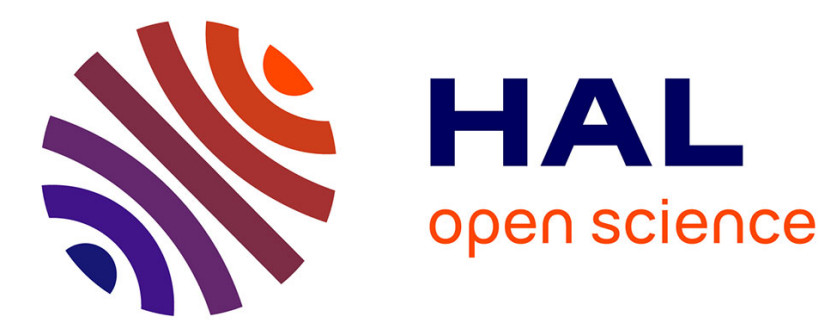

\title{
The Role of Embarrassment to Shape Public Interactions Licia Calvi
}

\section{To cite this version:}

Licia Calvi. The Role of Embarrassment to Shape Public Interactions. 14th International Conference on Entertainment Computing (ICEC), Sep 2015, Trondheim, Norway. pp.391-398, 10.1007/978-3319-24589-8_31. hal-01758414

\section{HAL Id: hal-01758414 \\ https://hal.inria.fr/hal-01758414}

Submitted on 4 Apr 2018

HAL is a multi-disciplinary open access archive for the deposit and dissemination of scientific research documents, whether they are published or not. The documents may come from teaching and research institutions in France or abroad, or from public or private research centers.
L'archive ouverte pluridisciplinaire HAL, est destinée au dépôt et à la diffusion de documents scientifiques de niveau recherche, publiés ou non, émanant des établissements d'enseignement et de recherche français ou étrangers, des laboratoires publics ou privés. 


\title{
The Role of Embarrassment to Shape Public Interactions
}

\author{
Licia Calvi \\ Academy for Digital Entertainment, NHTV University of Applied Sciences, Breda, \\ The Netherlands \\ calvi.l@nhtv.nl
}

\begin{abstract}
Can audience embarrassment be used to shape interactions in public settings? Is this the threshold for an audience to step in and / or out of the interaction in performative interactions in public space?

The proliferation of mobile and ubiquitous devices has shifted the attention to the design of interactive systems for use in public settings. This design applies the notion of performance to attract and engage audiences. Because performance becomes such a core part of the interaction, the success of those interactive systems heavily depends upon the physical, social and emotional context in which they are to be used. Indeed, strangers around a potential user may hinder or encourage that individual's participation in the interaction. Similarly, the physical space in which the interaction takes place, public or semi-public space may as well facilitate audience participation or prevent it.

This paper investigates what characteristics of this setting (perceived / felt) can trigger audience participation in the interaction. A model based on the notion of performance and entailing some degree of felt embarrassment is applied to two cases to explain how the potential embarrassment implicit in any interaction in public space can be used to encourage users' participation in it.
\end{abstract}

Keywords: Performance, public space, embarrassment, social norms, design to limit embarrassment

\section{$1 \quad$ Introduction}

Interacting with a system in a public setting is by far not straightforward for a potential audience, particularly if what is asked of them is to take part in a performative interaction that is one where performance lies at the core of the interaction itself. Because performing is in this case what users are expected to do, the success of those interactive systems heavily depends upon elements that have little to do with the system itself, but relate to the physical space and, particularly, to the social and emotional context in which the system is used. Indeed, strangers around a potential user may hinder as well as encourage that individual's participation in the interaction. Similarly, the physical space in which the interaction takes place, in the form of a public space like a train station or a semi-public space like a museum or a gallery, may as well facilitate audience participation or prevent it. 
Several recent studies [1], [3], [10-11] have shown for example the influence that the mere presence of strangers has on the individual's intention to participate or not to participate in these interactions. VideoMob [10], for instance, is an interactive art installation based on Kinect technology that encourages strangers to connect across space and time. By presenting this art installation in various locations and contexts through the United States, the authors could collect hundreds of participants' responses to the interactive system and analyse their social behaviors when interacting with strangers in public space, in an attempt to identify what makes people trespass that invisible embarrassing threshold when expected to perform in public space.

Similarly, Hespanhol and his colleagues [11] have observed social encounters around large media façades. It is interesting to see in this study how people approach the interactive space, how they behave differently depending on the relative distance they are from this physical space and on the social situation they are in (i.e., alone, with friends or with children). Especially adults seem restrained to perform, mostly tend to look for other adults and to remain confined in this small clique when engaging in these interactions but appear less reluctant to step out of their comfort zone in the presence of kids.

From these few examples we can already see how the others, especially when strangers, can "invoke feelings of shyness and a desire to control the personal exposure associated with interactions" [3].

This is why we intend to investigate how public embarrassment can be transformed into an opportunity to play. In [4], we have referred to the notion of experiential place [6], as the way for people to break the social norms holding in a given context (cultural institutions in that case) and cross their emotional threshold to perform in public by for instance lying in a concert hall to intensify the music experience or dressing up as a cockroach when visiting a science museum. In this paper, we will embed this notion into a model to limit embarrassment when designing interactions in public space. This model is built by observing existing examples of such interactions and borrows elements from other accepted models of performance in HCI (see further).

In the next sections, we will first define what performative interactions are and present two different cases of performative interactions, "Schizophrenic Cyborg" [1617] and "Presence" [7]. Further, we will describe the performance-based model we developed. We will then discuss the notion of felt embarrassment in the cases presented and analyse the way in which interaction can be shaped to limit embarrassment according to the model outlined.

\section{Performative interactions}

Williamson et al. [21] define performative interactions as "any interaction or technology that is influenced by or affected by the spectacle resulting from its use, the public setting where it is used, or the presence of spectators as an audience" [21, p. 1546].

Based on this definition, they identify two types of performative interactions: those where technology is part of the artistic expression and rely on a performer actually performing on some kind of stage (we call them performer-driven interactions), and 
those with no official performer where it is the technology that triggers an audience to participate (we call them technology-driven interactions). Recent examples of performer-driven performative interactions are Joe Malia's "Scarf" [13], Philips "Skin Probe Bubble" [14], various performances by Stelarc [18], and "Schizophrenic Cyborg" by Sheridan and colleagues [16-17]. Examples of technology-driven performative interactions are "Presence" by Laura Dekker [7], "SMS Slingshot" by VR/URBAN [20] or "Text Rain" by Camille Utterback and Romy Achituv [19].

In "Schizophrenic Cyborg" [16-17], a performer is facing an audience with a screen hanging on his belly. The interface on his body displays an interaction that is in fact activated by another performer who is not visible to the public. So "Schizophrenic Cyborg" represents an example of a performative interaction where the performer puts on stage a situation using technology as part of the play in order to express something (therefore a performer-driven interaction). The role technology has is to create a confusion or misconception in the audience between the interaction enacted through the interface and the ways to achieve it. The audience has indeed no clue that what is displayed on the performer's body is not controlled by him but that he is himself part of the technology on stage (from here the name "cyborg") and that he himself, like the interface, is manipulated by the hidden performer. Just seeing the effects of this interaction but not the interaction itself, nor the cyborg undertaking any action, can of course cause various reactions in the public: these are all used by the hidden performer to shape the actual interaction. The cyborg is part of the technology and of the representation on stage and as such is not aware of the kind of interactions that the hidden performer is enacting, that is what will be shown on the screen and what reactions in the audience trigger it. In doing so the cyborg/device only provides a tangible and visible source for dialogue, despite the invisibility of the enacting power (the hidden performer).

In "Presence" [7], screens are displayed in a park and require an audience to move or dance in front of them provoking with their movements layers of video to reveal or hide (Fig. 1).

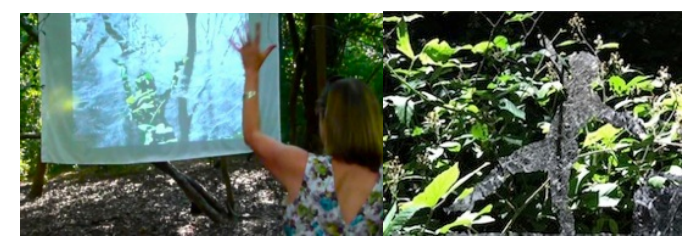

Fig. 1. Presence by Laura Dekker [7]

This is an example of a technology-driven performative interaction because the performance is determined by the audience movements that are triggered by the screen images. These screen images are related and engaged with the physical space, but they are not influenced by it, they are only affected by the social context, that is by the people present: who they are, what they do, if they play on their own or together. However, the audience willingness to perform or not is certainly affected by both. 
In different ways both works (and the kind of performative interactions they enact) play with the notion of audience embarrassment although in one work this is more prominent and direct than in the other: in Dekker's work, as something the audience has to cope with and to overcome in order to participate in the interaction; in Sheridan's work, embarrassment is more about being able to understand who is in control of what in order to be able to react in an appropriate way. So, in a way, while in Dekker's work embarrassment can be felt more strongly because each individual needs to stand up for themselves to perform, in Sheridan's work, the audience seems to act more as a whole against the cyborg/hidden performer.

Both works and the way they use embarrassment can be better understood by looking at them through the lens of the performance-based model of interaction (see below). This model is intended to help design to limit embarrassment, so that more audience can trespass the threshold to interaction and become engaged in the performance.

Embarrassment has been described by Goffman [8-9] as that something people feel (being not at ease, or restrained) every time they violate the implicit social norms holding in the environment they are in. Technology may force people to violate these norms whenever they are pushed to move from the status of audience to that of performers (see in next section), that is, when the behavior they perform is front stage, which happens when people are in the centre of somebody's attention. Dekker's artwork is an example of this: people are encouraged to behave differently, possibly playfully, in a context (certainly physical, maybe even social and this depending on the nature of the audience around them) that would normally not allow this kind of behaviour. What makes it possible? What makes people not feel embarrassed to adopt an otherwise socially unacceptable behaviour? The feeling of being watched by others indeed mostly induce people to change behaviour, in general to behave socially, that is according to the accepted rules.

\subsection{Models of performative interactions}

Several models of performative interactions have already been developed [2], [15], [17]. They are based on the idea that for an interaction to occur, different audience roles are needed (performer / participant / observer) and that the interaction is confined within a given space (physical and / or psychological) for the audience to recognise and within which specific behavioral codes (or interactions rules) apply. In some cases [2] and [15], these roles are not static but may change as a result of the interaction evolving.

These models however do not seem to consider appropriately the space and the experience thereof of the people involved in the performance, regardless of the role they play in the initial interaction. We believe that it is precisely this experience that can help them cross that emotional threshold to perform in public without feeling embarrassed. This specific experience of the space lies at the heart of the model we have developed, that we called the performance-based model (Fig. 2). 


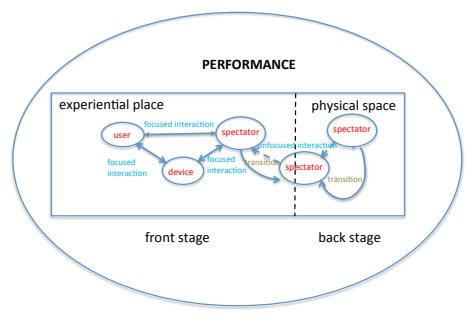

Fig. 2. The performance-based model

This model is very much in line with Benford's and Reeves's model [2] and [15] as it borrows from it audience differentiation and the notion of role transitions to account for the plasticity of the performative interaction. It also implies that these transitions must occur within a well-defined physical space. What we call performance in our model roughly corresponds to Reeves's performance frame [15] but our definition includes the physical and social context (the space) as well as its transformation into place. So it is in fact the context in which the performative interaction can ultimately take place. Here, the transition is from a physical space, i.e., the setting where the audience is and where the interaction can occur in practice, to an experiential place that is where the performance happens [4]. So the shift accounted for by this model is not physical rather it is cognitive. In a way, this experiential place is very similar to Huizinga's magic circle [12], in that the experience of it is not only memorable, but essentially meaningful. The recognition of this meaningfulness is what allows each individual participant to feel less unease in becoming a performer in front of an even unknown audience because they can add a personal meaning with each individual experience and in this way they can overcome their embarrassment to perform in public. Technology is part of this experience and in a way it is what makes the interaction possible especially in the technology-driven performative interactions discussed above.

The model in Figure 2 indeed displays the cognitive unfolding of the interaction rather than its ontological consistence. This unfolding is mainly visible in the transformation of the spectator moving from back to front stage [8-9], that is from being at the side of the interaction to being in the centre of it, and also from being part of an unfocused interaction, as a passer-by or a distracted observer, to a focused interaction, one the spectator is aware of and wittingly participating in. The performative interaction assumes the presence of a performer and a device (i.e., the technology in the definition by [21]) without specifying however the particular role this technology may take, or the function it may display. In this way, both forms of performative interactions mentioned above are accounted for. But their mere presence, of the performer and the device, is not enough: it is the spectator's transformation what sets the transition from physical space to experiential place in motion. This transformation implies 
the overcoming of some kind of felt embarrassment. In the next section, we will see how this model applies to the two cases presented earlier.

\section{Embarrassment in performative interactions}

If we apply the performance-based model to the two examples of performative interactions described above, we find different uses (or misuses) of it.

Dekker's performative interaction seems to apply the model in Fig. 2 almost literally: the audience has to recognise the possibility that, by stepping into the interaction, they will transform space into place by recognizing and attaching personal meanings to it. This recognition makes them forget about the physical and social setting they are in and their possible embarrassment with it. So, in this case (the possibly felt) embarrassment is part of the performative interaction, in fact it is essential for the interaction to take place, for people to recognize the magic circle [12] that allows them to step into the interaction and to play. Overcoming embarrassment is what makes the interaction possible. And passing this threshold is possible if users transform the physical space onto the experiential place.

In Sheridan's work on the contrary there is no physical space to be transformed, no experiential place to be filled with personal meanings, no magic circle to step into. There is a barrier between audience and performer / cyborg, and this is represented by the hidden performer, and by the interaction he is orchestrating behind the scene and without anybody being aware of: the audience that the messages are manipulated by others and not controlled by the performer / cyborg, the cyborg of what causes the audience's reactions. In this work therefore, the separation between physical space and experiential place remains and cannot be trespassed. The confusion and intended misconception generated by this set-up is what may cause embarrassment in the audience and in the cyborg but not one to be easily overcome by transforming space into place. Sheridan et al. [17] indeed report that the audience could recognize how the interaction was taking place (so that the cyborg was not in control of it) only if they had a high technical expertise: so nothing to do with the experience of stepping into the magic circle discussed above.

The question remains whether this effect is intrinsic in all performer-driven performative interactions that only use technology on stage or whether this is one of its possible uses. And whether from an HCI point of view one can appropriately speak of performative interactions only in the case where an audience is more actively engaged as in Dekker's example (so for technology-driven performative interactions).

\section{Conclusion}

In this paper, we have presented a model to explain performative interactions in public space, one that takes the possibility of participants' embarrassment into account and proposes a way to overcome it. A design for interactions in public space to limit embarrassment should account for a cognitive transformation of a physical space into an experiential place, one where the audience can feel emotions, have memorable 
experiences, attach meanings to it in a continuous and interactive way. This is when space becomes place.

The two cases discussed in this paper represent different yet specular instances of performative interactions. We have explained their different use of audience embarrassment under the light of a performance-based model of interaction. This model is in fact meant to limit embarrassment and to encourage audience engagement in the performative interaction. However, opposite uses (or misuses) are possible. Playing with the (im)possibility to shift from physical space to experiential place allows that.

The results of this analysis are very preliminary and do not allow for generalizations. However, they show that only in one type of performative interaction, the technology-driven one where technology is triggering the interaction as in Dekker's artwork, the concept of audience embarrassment can be appropriately applied as something that needs to be overcome in order to step into the interaction. As what shortens the distance among people (all actors) and makes people shift from a physical space to an experiential place and experience the interaction as pervaded with personal meanings. In the other type of performative interactions, the one where technology is part of the representation on stage (performer-driven), more uses seem to be possible and all depend on the performer's intentions. In the example discussed here, the (hidden) performer intended to create confusion and mislead the audience into believing that the cyborg was responsible for the interaction while he was also part of it in his dual role of performer and of technology (medium and message). Other performative interactions of this type (for instance Cillari's Se mi sei vicino [5]) still open up spaces for a dialogue with the audience and for this transformation (from space to place) to occur. Also here the performer is in fact in control of the interaction and the technology part of this stage representation. But the audience is 'pushed' to get closer (in 'Cillari's work literally and also physically).

These observations do not allow us to draw any final conclusion on the absolute validity of the model presented but advocate for more research on the types of performative interactions existing, their use of technology and the type of setting, both emotional, social and physical, they are embedded into.

Several questions still remain unanswered, in fact: what type of design can trigger users to cross the threshold? What elements should be present in the physical space to encourage this? Can we draw some guidelines on how to actually implement this design? Has the size of the audience an effect on the individual's intention to participate in the public interaction?

Acknowledgements. The author wishes to thank Laura Dekker for sharing her work with her.

\section{References}

1. Bekker, T., Johansen, S., van Kuijk, M., Schouten, B., Sturm, J., Vanden Abeele, V.: Playful Interactions Stimulating Physical Activity in Public Spaces. In Proc. CHI 2013 Workshop, Experiencing Interactivity in Public Spaces (2013) 
2. Benford, S., Crabtree, A., Reeves, S., Sheridan, J., Dix, A., Flintham, M., \& Drozd, A.: The frame of the game: Blurring the boundary between fiction and reality in mobile experiences. In: Proceedings SIGCHI 2006, 427-436. ACM Press (2006)

3. Calcraft, P., Chalmers, D., Fisher, C., Rimmer, J., Wakeman, I., Whiting, L.: Mediating Exposure in Public Interactions. In: Proc. CHI 2013 Workshop, Experiencing Interactivity in Public Spaces (2013)

4. Calvi, L. and Spence, J.: Engaging Audiences in Museums in a Performance Way. In: Proceedings of DRHA2014 conference. University of Greenwich's London eScholarship Repository (In press)

$\begin{array}{llllll}\text { 5. Cillari, } & \text { S.: } & \text { Se } & \text { mi } & \text { sei } & \text { vicino. }\end{array}$ http://www.soniacillari.net/Se_Mi_Sei_Vicino_.htm

6. Ciolfi, L. and Bannon, LJ: Space, place and the design of technologically-enhanced physical environments. In: Proc. INTERACT 2015 Workshop, Workshop on Place and Experience in Human-Computer Interaction (2005)

7. Dekker, L.: Presence (2012). http://theretohere.co.uk/There_to_Here/Presence.htm

8. Goffman, E.: The presentation of self in everyday life. Doubleday, Garden City, NY (1959)

9. Goffman, E.: Behavior in Public Places; Notes on the Social Organization of Gatherings. Free Press of Glencoe, NY (1966)

10. Grenader, E., Rodrigues, D.G., Nos, F. and Weibel, N.: The VideoMob Interactive Art Installation Connecting Strangers through Inclusive Digital Crowds. In: Salah, A., Hung, H., Aran, O., Gunes, H. and Turk, M. (eds), "Behavior Understanding for Arts and Entertainment", special issue, ACM Transactions on Interactive Intelligent Systems (TiiS) (In press)

11. Hespanhol, L., Tomitsch, M., Bown, O. and Young, M.: Using Embodied Audio-Visual Interaction to Promote Social Encounters Around Large Media Façades. In: Proc. DIS 2014, 945-954. ACM Press (2014)

12. Huizinga, J.: Homo Ludens: A Study of the Play-Element in Culture. London: Routledge \& Kegan Paul (1949)

13. Malia, J. Private Public. Retrieved from: http://design-interactions2007-2014.rca.ac.uk/joemalia/private-public

14. Philips Skin Probe Bubble. Retrieved from: http://www.design.philips.com/philips/sites/philipsdesign/about/design/designportfolio/desig n_futures/dresses.page

15. Reeves, S.: Designing interfaces in public settings. Thesis submitted to The University of Nottingham for the degree of Doctor of Philosophy (2008)

16. Schizophrenic Cyborg. Retrieved from: http://www.bigdoginteractive.com/cyborg.htm

17. Sheridan, J. G., Dix, A., Lock, S., \& Bayliss, A.: Understanding interaction in ubiquitous guerrilla performances in playful arenas. In: People and Computers XVIII-Design for Life, 3-17 (2005)

18. Stelarc, http://stelarc.org/_.swf

19. Utterback, C. and Achituv, R. Text Rain. http://camilleutterback.com/projects/text-rain/

20. VR/URBAN, SMS, Slingshot. Retrieved from: http://www.vrurban.org/smslingshot.html

21. Williamson, J.R., Koefoed Hansen, L., Jacucci, G., Light, A., and Reeves, S.: (eds), Understanding performative interactions in public settings. Pers Ubiquit Comput) 18 (2014) 